\title{
Recurrent Parathyroid Gland Carcinoma
}

National Cancer Institute

\section{Source}

National Cancer Institute. Recurrent Parathyroid Gland Carcinoma. NCI Thesaurus. Code C7828.

The reemergence of parathyroid gland carcinoma after a period of remission. 